\title{
Linguistics meets "legalese": syntax, semantics, and jury instruction reform
}

Janet Randall ${ }^{1}$ and Lucas Graf

LSA Annual Meeting, Minneapolis, January 2-5, 2014

1. Background. A movement is underway across the U.S. to reform jury instructions, the instructions that a judge reads to the jurors before they repair to the jury room to reach a verdict. California revised its jury instructions in 2003, because jurors found many of them incomprehensible and sometimes returned misinformed verdicts (Benson, 1984; Marder, 2006). As (1) illustrates, Massachusetts' instructions pose the same problem.
Negligence is the failure of a responsible person, either by omission or by action, to exercise that degree of care, diligence, and forethought which, in the discharge of the duty then resting on him or her, the person of ordinary caution and prudence ought to exercise under the particular circumstances. It is a want of diligence commensurate with the requirement of the duty at the moment imposed by the law... ${ }^{1}$

Full of linguistic features that tax comprehension -- passive verbs (Gough 1966; Ferreira 2003), nominalizations (Klare 1973), negatives (Wason 1972; Just \& Clark 1973; Just \& Carpenter 1976; Cutler 1983), omitted arguments; low-frequency, formal-register, and presupposed or undefined terminology), such instructions have been shown to confuse even highly educated jurors, never mind jurors with less education or non-native English skills (Charrow \& Charrow 1979; Elwork, et. al. 1982; Diamond \& Levi 1996; Diamond 2003; Tiersma 1999, 2001, 2009).

In our 2013 LSA talk (Randall et. al, 2013), Massachusetts Plain English Jury Instruction Project), we showed that current instructions are harder to understand than Plain English versions. But, difficulty varied, and here we show why. Two specific linguistic features correlate with comprehension rates: (1) passive verbs and (2) presupposed terms. Subjects score high on instructions with low rates of both passives and presupposed terms, and vice versa.

2. Earlier research (Randall et. al. 2013). We hypothesized that (1) Current Jury Instructions are harder to understand than Plain English Jury Instructions and (2) processing difficulty will vary based on linguistic factors. In this study, two groups of subjects (29 in each), all Northeastern University students, listened to digital recordings of six instructions (plus one "warm-up") and answered true/false questions after each instruction. Group 1 heard Current Instructions, Group 2, Plain English Instructions. As Figure 1 shows, the proportion of questions correctly answered by $\geq 90 \%$ of subjects different significantly in the two groups: $30 \%$ for Current instructions vs. 52\% for Plain English $(\mathrm{p}<.05)$.

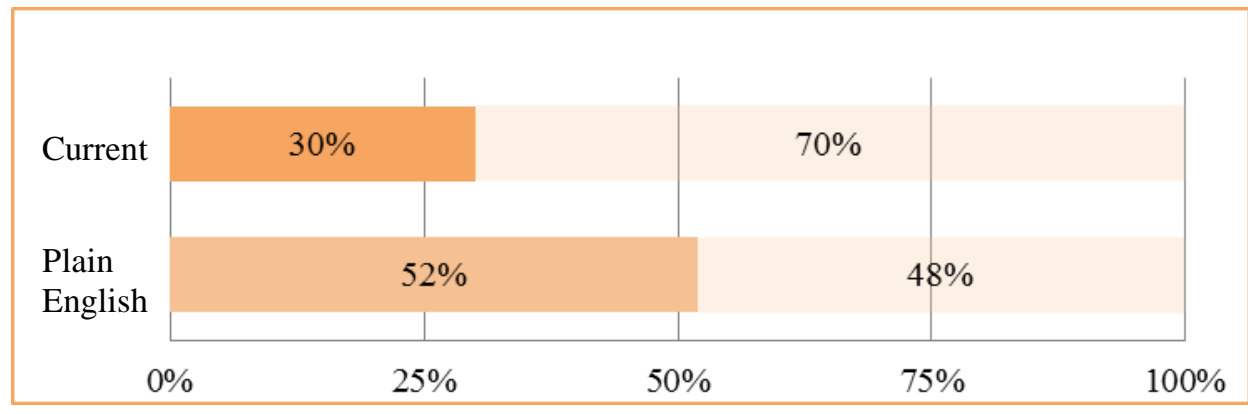

Figure 1. Proportion of questions answered correctly by $\geq 90 \%$ of subjects

\footnotetext{
${ }^{1}$ Thanks to our research assistants and to the Mass. Bar Association for sponsoring Janet Randall as a 2012-14 Research Fellow. Authors: Janet Randall, Northeastern U. (andall@ neu.edu), Lucas Graf, NU alumnus (lucasrgraf@ gmail.com).
} 
However, as Figure 2 shows, the Current Jury Instructions were not found to be equally difficult. Comprehension rates for Instructions 1-2 were significantly higher than 3-6: 88-89\% vs. 61-77\% $(z=-3.12, p<.01)$. The question we left unanswered was: Why?

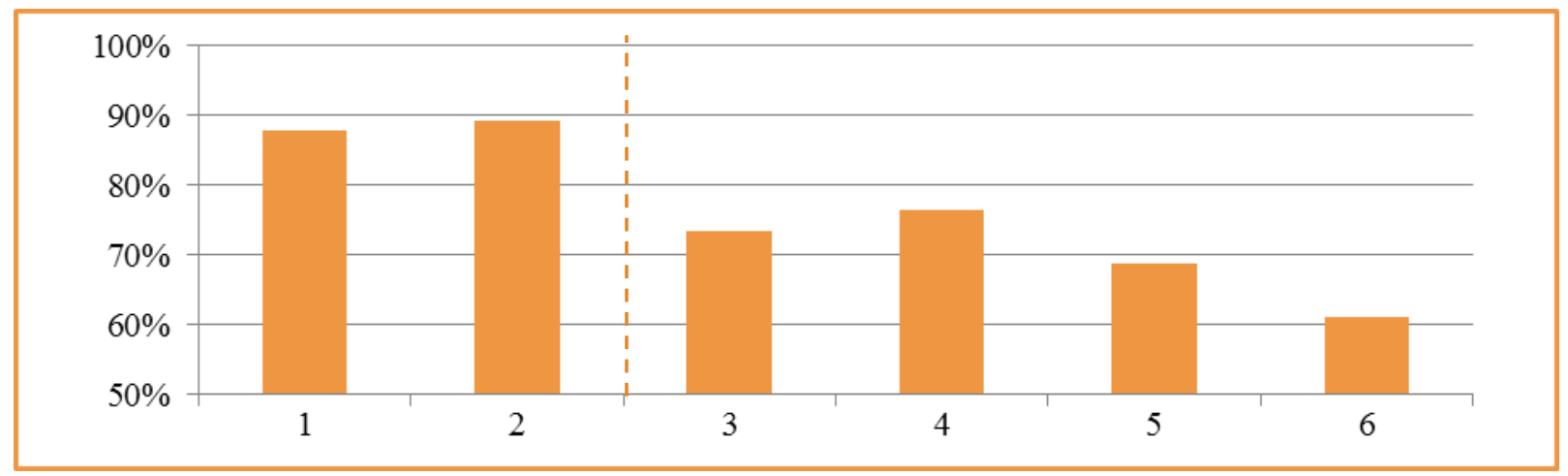

Figure 2. Subject Performance: Current Jury Instructions

3. The current study. In this follow-up, we hypothesized that the variation across the Current Jury Instructions (Figure 3a) would be related to two linguistic factors, passive verbs (3b) and presupposed terms (3c). And this was the case. The results clustered in two groups: "easy" Instructions $1 \& 2$ had lower rates of these factors; "difficult" Instructions 3-6, higher rates.

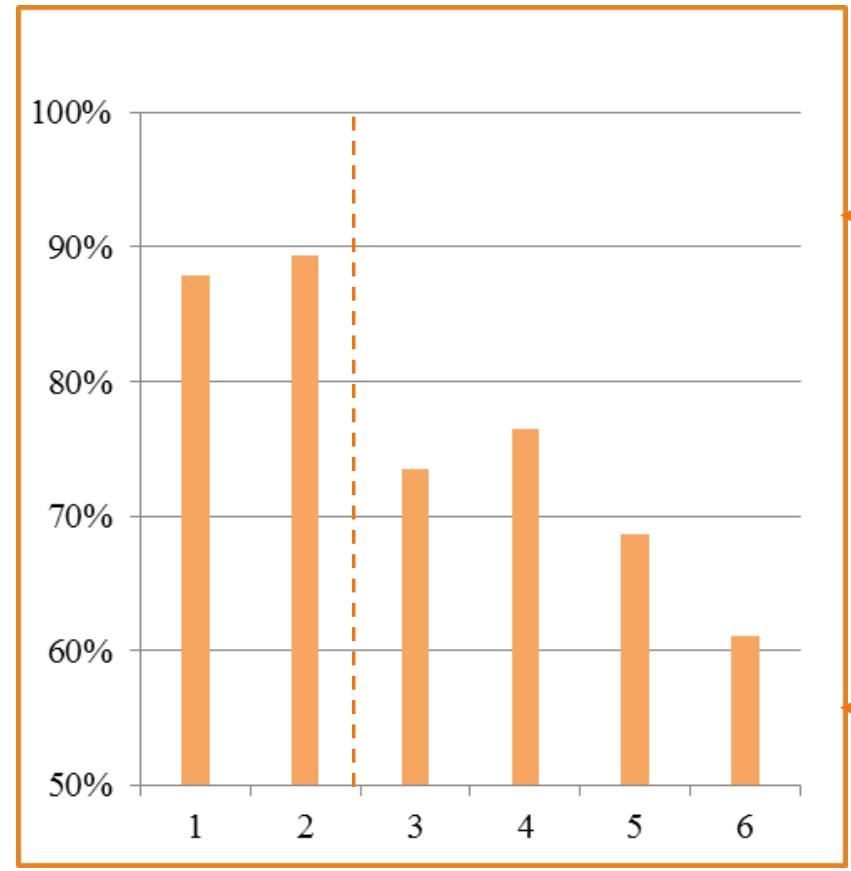

Figure 3a. Subject Performance: Current Jury Instructions

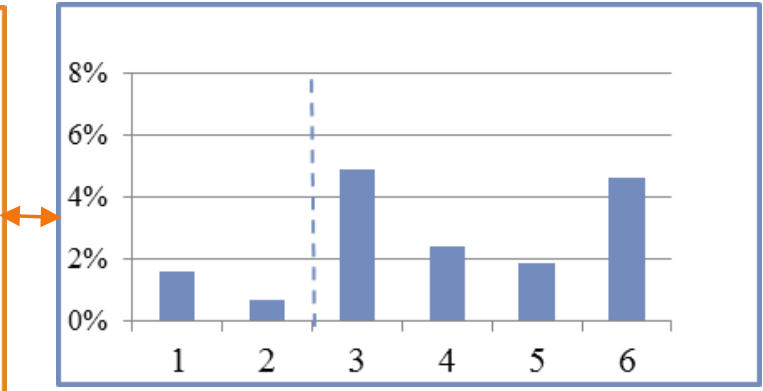

Figure 3b. Passive verbs / total words

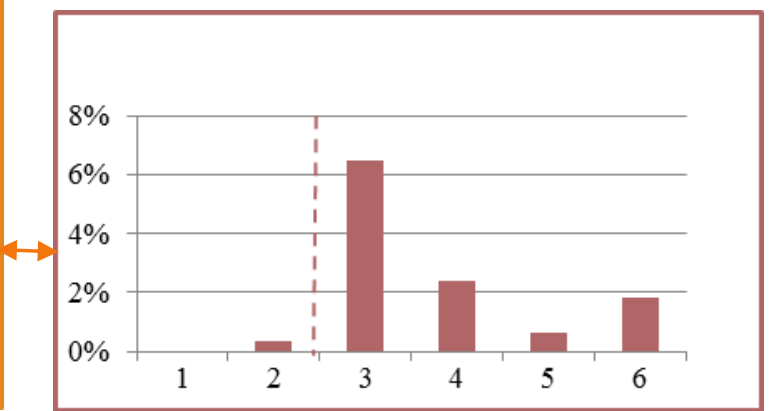

Figure 3c. Presupposed terms / total words

Consequently, the switch to Plain English had a greater impact on Instructions 3-6, as shown in Figure 4a. As we would predict, the greatest difference, for Instruction 6 (circled), $61 \%$ vs. 82\% $(z=-2.86, p<.01)$, corresponds to the greatest differences in the rates of (4b) passive verbs $(5 \%$ vs. $1 \%)$ and $(4 \mathrm{c})$ presupposed terms $(2 \%$ vs. $0 \%)$. The other five instructions showed similar correlations between improvement and rates of these two factors (not reported here). The difference in language of the two versions of Instruction 6 are displayed in Figure 5, with passives shown in square brackets and presupposed terms in curly brackets. 


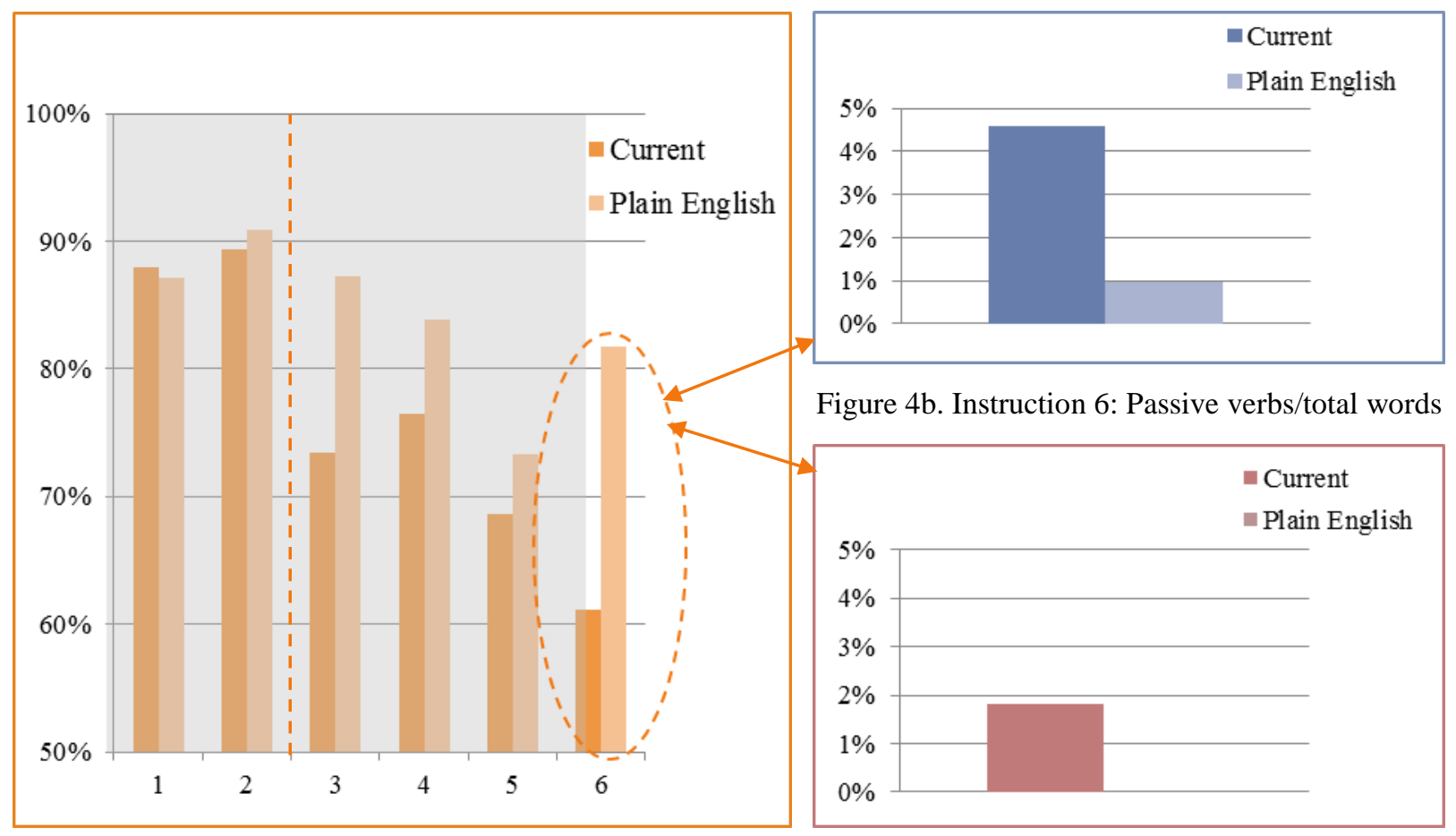

Figure 4a. Subject Performance: Current Jury Instructions

Figure 4c. Instruction 6: Presupposed terms/total words

\section{Current Version}

There are two types of evidence that you may use to determine the facts of a case: direct evidence and circumstantial evidence. You have direct evidence where a witness \{testifies directly\} about the fact that [is to be proved], based on what (he/she) claims to have seen or heard or felt with (his/her) own senses, and the only question is whether you believe the witness. You have circumstantial evidence where no witness can \{testify directly\} about the fact [that is to be proved], but you [are presented] with evidence of other facts and then asked to draw reasonable inferences from them about the fact that [is to be proved]. (Brady et. al., 2008).

\section{Plain English Version}

You have heard evidence that you must use to decide what the facts are in this case. There are two types of evidence. One type [is called] direct evidence, which is what a witness claims to have seen or heard or smelled. So a witness saying that she saw a mailman put mail into her mailbox is direct evidence that the mailman delivered her mail. The other type of evidence is indirect or "circumstantial" evidence. A witness saying that she saw that her mailbox was empty when she left the house and full when she came home is indirect evidence that the mailman delivered her mail. Indirect evidence allows you to reach the same conclusion as direct evidence, but you have to make an inference -- a logical connection -- to get there. It makes no difference whether evidence is direct or indirect. One is not better than the other.

Figure 5. Jury Instruction 6: Direct and Circumstantial Evidence

4. Conclusions and implications: Our findings confirm our hypotheses: (1) Current jury instructions are more difficult to understand than Plain English jury instructions and (2) linguistic factors - passive verbs and presupposed terms - do contribute to processing difficulty. Lower rates of passive verbs and presupposed terms correlated with better comprehension; higher rates, with worse comprehension. Thus, rewriting jury instructions in "Plain English," with a specific focus on minimizing these factors can significantly improve comprehension. In 2005, the American Bar Association wrote: "All instructions to the jury should be in plain and understandable language" (Diamond et. al., 2012) yet, even now, collaborations between legal professionals and linguists are rare (Solan 1999; Solan \& Tiersma 2005). But results like ours suggest ways to implement reform. If the legal community pays attention, linguistic evidence could play an important role in improving jurors' understanding, making verdicts more reliable and the judicial system more fair. 


\section{References}

Benson, R. 1984. The End of Legalese: the game is over. NYU Review of Law and Social Change 13, 519-574. http://www.courts.ca.gov/partners/documents/caci_2012_edtion.pdf

Charrow, Robert P. \& Veda R. Charrow. 1979. Making Legal Language Understandable: A Psycholinguistic Study of Jury Instructions. Columbia Law Review 79, 1306-1374.

Cutler, A. (1983) Lexical Complexity and Sentence Processing in Flores d'Arcais, G. \& R. Jarvella, The Process of Language Understanding, Wiley, N.Y.

Diamond, Shari S. 2003. "Truth, Justice and the Jury," Harvard Journal of Law \& Public Policy 26, 143-155.

Diamond, Shari S. \& Judith N. Levi. 1996. Improving Decisions on Death by Revising and Testing Jury Instructions, Judicature, 79, 224 -231.

Diamond, Shari S. Beth Murphy \& Mary R. Rose (2012) The "kettleful of law" in real jury deliberations: successes, failures, and next steps. Northwestern University Law Review 106, No. 4, 1537- 1608.

Elwork, Amiram, Bruce D. Sales \& James J. Alfini. 1982. Making Jury Instructions Understandable. Michie, Charlottesville, VA.

Ferreira, F. 2003. The misinterpretation of noncanonical sentences. Cognitive Psychology 47,164-203.

Gough, Philip B. 1966. "The verification of sentences: The effects of delay of evidence and sentence length." Journal of Verbal Learning and Verbal Behavior 5.5 ,492-496.

Just, M. A., \& Carpenter, P. A. 1976. Eye fixations and cognitive processes. Cognitive Psychology, 8, 441-480.

Just, M. A., \& Clark, H. H. 1973. Drawing inferences from the presuppositions and implications of affirmative and negative sentences. Journal of Verbal Learning and Verbal Behavior, $12,21-31$.

Klare, G. R. 1976. A second look at the validity of the readability formulas. Journal of reading behavior 8, 159-152.

Marder, Nancy. 2006. Bringing Jury Instructions into the Twenty-First Century, Notre Dame Law Review, 81, 451-470.

Olson, David R. \& Nikola Filby. 1972. "On the comprehension of active and passive sentences." Cognitive Psychology 3.3 361-381.

Randall, Janet. 2013. Plain English Jury Instructions for Massachusetts: first steps. Paper presented at the Linguistics Society of America Annual Meeting, Boston, MA.

Slobin, D. I. 1966. Grammatical transformations and sentence comprehension in childhood and adulthood. Journal of Verbal Learning and Verbal Behavior, 5, 219-227.

Solan, Lawrence M. 1999. Refocusing the Burden of Proof in Criminal Cases: Some Doubt About Reasonable Doubt, Texas Law Review 78, 105-147.

Solan, Lawrence M. \&, Peter M. Tiersma. 2005. Speaking of Crime: The Language of Criminal Justice. Chicago, University of Chicago Press.

Tiersma, Peter M. 2009. Communicating with Juries: How to Draft More Understandable Jury Instructions. Loyola-LA Legal Studies Paper No. 2009-44. Available at SSRN: http://ssrn.com/abstract=1507298. (30 July, 2014.)

Tiersma, Peter M. 2001. The Rocky Road to Legal Reform: Improving the Language of Jury Instructions. Brooklyn Law Review 66, 1081-1118.

Tiersma, Peter M. 1993. Reforming the Language of Jury Instructions. Hofstra Law Review 22, 37- 78.

Tiersma, Peter M. 1999. Jury Instructions in the New Millennium. Court Review 36, 28-36.

\footnotetext{
${ }^{1}$ Brady, Patrick E. et. al. 2008. Massachusetts Superior Court Civil Practice Jury Instructions § 1.8.2 Direct and Circumstantial Evidence Massachusetts Continuing Legal Education, Inc. Boston, MA.
} 